\title{
Sesquiterpene lactone 6-O-angeloylplenolin reverses vincristine resistance by inhibiting YB-1 nuclear translocation in colon carcinoma cells
}

\author{
CHANGLONG LI ${ }^{1,2}$, HEZHEN WU ${ }^{3}$, YANFANG YANG ${ }^{3}$, JIANWEN LIU ${ }^{2}$ and ZHENWEN CHEN ${ }^{1}$ \\ ${ }^{1}$ School of Basic Medical Science, Capital Medical University, Beijing 100069; ${ }^{2}$ School of Pharmacy, \\ East China University of Science and Technology, Shanghai 200237; ${ }^{3}$ Key Laboratory of Resources and Chemistry of \\ Chinese Medicine of The Ministry of Education, Hubei University of Chinese Medicine, Wuhan, Hubei 430061, P.R. China
}

Received August 26, 2017; Accepted February 9, 2018

DOI: $10.3892 / \mathrm{ol} .2018 .8592$

\begin{abstract}
Multidrug resistance (MDR) is a major obstacle to cancer chemotherapy efficacy. In the present study, 6-O-angeloylplenolin repressed the overexpression of ATP binding cassette subfamily B member 1 (MDRl) and increasing the intracellular concentration of anticancer drugs. A reduction in P-glycoprotein expression (encoded by $M D R 1$ ) was observed in parallel with a decline in mRNA expression in vincristine-resistant HCT (HCT-8/VCR) cells treated with 6-O-angeloylplenolin. In addition, 6-O-angeloylplenolin suppressed the activity of the MDRl gene promoter. Treatment with 6-O-angeloylplenolin also decreased the amount of the specific protein complex that interacted with the MDRl gene promoter in HCT-8/VCR cells, potentially leading to the suppression of $M D R 1$ expression. Treatment with 6-O-angeloylplenolin inhibited the nuclear translocation of Y-box binding protein-1 in HCT-8/VCR cells treated with 6-O-angeloylplenolin, contributing to the negative regulation of MDRl. Finally, 6-O-angeloylplenolin reversed VCR resistance in an HCT/VCR xenograft model. In conclusion, 6-O-angeloylplenolin exhibited a MDR-reversing effect by downregulating $M D R l$ expression and could represent a novel adjuvant agent for chemotherapy.
\end{abstract}

Correspondence to: Dr Jianwen Liu, School of Pharmacy, East China University of Science and Technology, 130 Menlong Road, Xuhui, Shanghai 200237, P.R. China

E-mail: czwen@ccmu.edu.cn

Dr Zhenwen Chen, School of Basic Medical Science, Capital Medical University, 10 Youanmen Xitoutiao Road, Fengtai, Beijing 100069, P.R. China

E-mail: czwenteam@163.com

Key words: 6-O-angeloylplenolin, colon carcinoma, vincristine, multidrug resistance, MDR1, YB-1, nuclear translocation

\section{Introduction}

Multidrug resistance (MDR) is a major obstacle to successful cancer chemotherapy. MDR is often associated with the overexpression of the ATP binding cassette subfamily B member $1(A B C B 1$, also known as $M D R 1)$ gene, which encodes P-glycoprotein (P-gp) $(1,2)$. P-gp expression enhances drug efflux pump activity, depleting the intracellular concentration of anticancer drugs, driving drug resistance. Various environmental stimuli, including an inverted CCAAT box, can activate the $M D R 1$ promoter (3-5), which directly interacts with Y-box-binding protein (YB-1) (5-9). Assays into MDRl promoter activity using reporter genes demonstrated that the nuclear translocation of YB-1 was able to activate the MDRI promoter $(5,7)$, contributing to the expression of $M D R 1$ and to drug resistance $(5,9)$. In addition, the expression of $M D R I$ was also observed in tumor specimens derived from cancer patients (9-11). Therefore, the nuclear localization of the YB-1 is a notable marker of disease progression (6). Moreover, multidrug resistance-associated protein 1 (MRP1) is a protein encoded by the ABCC1 gene in human, which may interacted with MDR1 to regulate the drug resistant as well (12). However, a previous study revealed that the amount of nuclear YB-1 was not associated with $M D R l$ expression (13). The mechanism of YB-1 nuclear translocation is presently unclear, meaning that further research is required.

The sesquiterpene lactone 6-O-angeloylplenolin, a bioactive component of Centipeda minima (L.) A (14), has been reported to have various biological activities, including antiprotozoal and antibacterial activities (15). It was previously reported that 6-O-angeloylplenolin induced apoptosis through a mitochondrial/caspase pathway in acute promyelocytic leukemia HL-60 cells (16); it was also reported to trigger mitotic arrest and caspase-dependent apoptosis in human multiple myeloma cells (17). The result of proteome microarray analysis revealed that 6-O-angeloylplenolin inhibited S-phase kinase-associated protein 1 (Skp1) and signal transducer and activator of transcription 3 to repress Skp2, exhibiting inhibitory effects on lung cancer cell proliferation (18). In addition, it was reported that a number of sesquiterpene lactones could bind specifically to human P-gp and reverse cellular multidrug 
resistance (19). However, the detailed mechanism behind the 6-O-angeloylplenolin-dependent rescue of drug resistance in cancer was not revealed. The present study demonstrated that 6-O-angeloylplenolin exhibited MDR-reversing activity in colon carcinoma cells and attempted to investigate the underlying mechanisms behind this reversal.

\section{Materials and methods}

Chemicals, cell lines and cell culture. 6-O-angeloylplenolin (also known as brevifolin or brevilin-A) (Fig. 1A) was isolated from $C$. minima in Capital Medical University (Beijing China), as described previously (17). The purity of 6-O-angeloylplenolin was $>97 \%$ (HPLC). The human colon carcinoma HCT-8 cell line and its MDR variant HCT-8/VCR were obtained from the Type Culture Collection of the Chinese Academy of Sciences (Shanghai, China). Cells were maintained in RPMI 1640 (Life Technologies; Thermo Fisher Scientific, Inc., Waltham, MA, USA) supplemented with $10 \%$ heat-inactivated fetal bovine serum (Life Technologies; Thermo Fisher Scientific, Inc.), penicillin $(100 \mathrm{ng} / \mathrm{ml})$ and streptomycin $(100 \mathrm{ng} / \mathrm{ml})$ in a humidified atmosphere with $5 \% \mathrm{CO}_{2}$ at $37^{\circ} \mathrm{C}$. HCT-8/VCR cells were grown under the same conditions, but the medium contained $2 \mathrm{mg} / 1$ vincristine (Sigma Aldrich; Merck KGaA, Darmstadt, Germany), which was removed for 1 week prior to assay commencement. In terms of cell proliferation and cell cycle distribution, there was no significant difference between these two cell lines.

MTT assay. The MTT colorimetric assay was performed as described by Mosman et al (20). HCT-8 or HCT-8/VCR cells were seeded into 96 -well plates at a density of $1 \times 10^{4}$ cells/well. The cytotoxicity of 6-O-angeloylplenolin, vincristine, mitomycin (Sigma Aldrich; Merck KGaA), hydroxycamptothecin (Sigma Aldrich; Merck KGaA) or the compounds in combinations in HCT-8 and HCT-8/VCR cells was analyzed by MTT assay following incubation of cells with these compounds for $24 \mathrm{~h}$. The concentrations of vincristine, mitomycin or hydroxycamptothecin were 1, 3, 10, 30, 100 and $300 \mu \mathrm{g} / \mathrm{ml}$. The cytotoxicity was expressed as the half-maximal inhibitory concentration $\left(\mathrm{IC}_{50}\right)$, which was extrapolated from linear regression analysis of experimental data.

Detection of intracellular vincristine accumulation. High-performance liquid chromatography (HPLC) was used to measure the accumulation of drugs in cells and tissue, as described previously (21). HCT-8/VCR cells were incubated with 6-O-angeloylplenolin for $24 \mathrm{~h}$ and then the cells were treated with $80 \mu \mathrm{g} / \mathrm{ml}$ vincristine for $12 \mathrm{~h}$. A total of $1 \times 10^{6}$ cells were collected and centrifuged at $4^{\circ} \mathrm{C}$ for $10 \mathrm{~min}$ at $15,996 \mathrm{x}$. The supernatant was discarded. The cell pellet was resuspended and lysed (Cell Signaling Technology, Inc. Danvers, MA, USA) for $10 \mathrm{~min}$ at $4^{\circ} \mathrm{C}$. A total of $50 \mu \mathrm{l}$ cell lysate samples were taken for HPLC evaluation. The concentrations of vincristine were determined by HPLC as described by Chinese pharmacopoeia (22). Briefly, separation was performed on $\mathrm{C}_{18}$ column (Eclipse $\mathrm{C}_{18}, 150$ by $4.6 \mathrm{~mm}$, with a particle size of $5 \mu \mathrm{m}$; Agilent Technologies, Inc., Santa Clara, $\mathrm{CA}, \mathrm{USA})$ at $20^{\circ} \mathrm{C}$. The mobile phase was a 55:45 (v/v) mixture of methanol and $60 \mathrm{mM}$ sodium phosphate buffer $(\mathrm{pH} 3.0)$. The UV detector was set at wavelength of $297 \mathrm{~nm}$. Data were expressed as the ratio of the peak area to that of the internal standard.

Adriamycin and Rh123 accumulation assay. Accumulation of the fluorescent compounds adriamycin (Sigma-Aldrich; Merck KGaA) and Rh123 (0.5 mg/ml; Sigma-Aldrich; Merck $\mathrm{KGaA}$ ) were used as a functional index of P-gp, as described previously $(5,23)$. HCT-8/VCR cells $\left(1 \times 10^{4}\right.$ cells/well) were first treated with $0.35,0.7$ and $1.4 \mu \mathrm{M}$ 6-O-angeloylplenolin for $24 \mathrm{~h}$. Next, one group of cells were treated with $12 \mu \mathrm{M}$ verapamil for $12 \mathrm{~h}$, which was used as the positive control (24). Following this, the cells were incubated in medium containing $50 \mu \mathrm{M}$ adriamycin and $10 \mu \mathrm{M}$ Rh123 for $3 \mathrm{~h}$. Finally, the cells were washed twice with PBS prior to measurement. The fluorescence intensity of were detected by fluorospectrophotometer (Synergy 2, BioTek Instruments, Inc., Winooski, VT, USA) for Rh123 at $530 \mathrm{~nm}$ (excitation wavelength, $500 \mathrm{~nm}$ ) and adriamycin at $530 \mathrm{~nm}$ (excitation wavelength, $485 \mathrm{~nm}$ ).

Determination of gene expression by reverse transcriptionquantitative polymerase chain reaction ( $R T-q P C R)$. HCT-8/VCR cells were treated with $1.4 \mu \mathrm{M}$ 6-O-angeloylplenolin for $12 \mathrm{~h}$. Total RNA was isolated by RNeasy Mini kit 250 (cat. no. 74106; Qiagen GmbH, Hilden, Germany) from HCT-8 or HCT-8 cells. QuantiTect Reverse Transcription kit 200 (cat. no. 205313; Qiagen GmbH) was used to synthesize complementary DNA (cDNA), according to manufacturer's protocol. The synthesized cDNA was subjected to RT-qPCR using QuantiTect SYBR ${ }^{\circledR}$ Green RT-PCR kit (Qiagen GmbH) on a Bio-Rad CFX Connect real-time PCR detection system (Bio-Rad Laboratories, Hercules, CA, USA) with conditions of 30 cycles of $40 \mathrm{sec}$ at $95^{\circ} \mathrm{C}, 40 \mathrm{sec}$ at $60^{\circ} \mathrm{C}$ and $30 \mathrm{sec}$ at $72^{\circ} \mathrm{C}$. The primers used for PCR were shown below: $M D R 1$ forward, 5'-CGAAACCGT ATCAGTCCTCG-3' and reverse, 5'-CTTGAGTCTGAGAGA CCACC-3' (25); MRP1 forward, 5'-GTGGAATTCCGGAAC TAC-3' and reverse, 5'-CGGAGGTCGTGCAGGCCG-3' (24); $Y B X 1$ forward, 5'-CGGAGGCAGCAAATGTTA-3' and reverse, 5'-CACCCTGGTTGTCAGCAC-3' (4); and GAPDH forward, 5'-GTCAACGGATTTGGTCGTATT-3' and reverse, 5'-AGTCTTCTGGGTGGCAGTGAT-3'. The PCR products were separated by electrophoresis on an $1.5 \%$ agarose gel and stained with $0.1 \mu \mathrm{g} / \mathrm{ml}$ ethidium bromide. Differential gene expression was quantified using the Image Analysis system, version 3 (FR-980A gel Image Analysis System, Shanghai Furi Science and Technology Co., Ltd., Shanghai, China).

Flow cytometry assay. HCT-8/VCR cells were treated with $0.35,0.7$ or $1.4 \mu \mathrm{M} 6-\mathrm{O}$-angeloylplenolin for $24 \mathrm{~h}$, and flow cytometry was performed. A total of $1 \times 10^{5}$ cells $/ \mathrm{ml}$ cells were washed in PBS with $0.1 \%$ sodium azide (PBS-azide). The cells were firstly blocked with $3 \%$ Bovine Serum Albumin (BSA) at room temperature for $1 \mathrm{~h}$. Then, HCT-8/VCR cells were incubated with $2 \mu \mathrm{g}$ monoclonal antibodies against P-gp (Aviva Systems Biology, Corp., San Diego, CA, USA; cat. no. APR51326_P050) at a dilution of 1:100 for $2 \mathrm{~h}$ at room temperature. Next, cells were washed twice with PBS and incubated with $1 \mu \mathrm{g}$ goat anti-rabbit secondary antibodies 

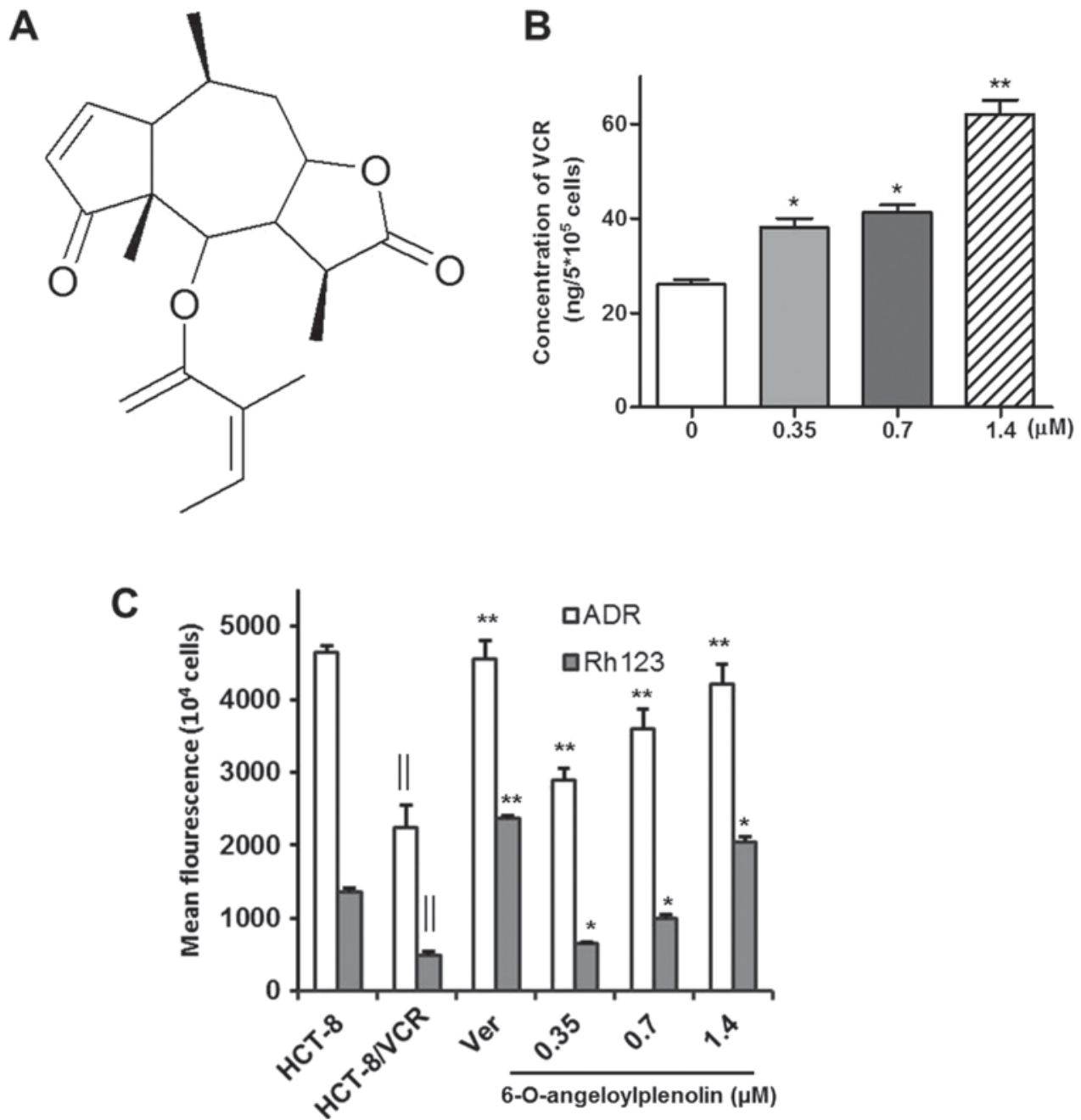

Figure 1. Chemical structure of 6-O-angeloylplenolin and effect of 6-O-angeloylplenolin on the intracellular accumulation of vincristine, adriamycin and Rh123. (A) The Chemical structure of 6-O-angeloylplenolin. (B) HCT-8/VCR cells were incubated with $80 \mu \mathrm{g} / \mathrm{ml}$ vincristine for $12 \mathrm{~h}$ following treatment with 6-O-angeloylplenolin for $24 \mathrm{~h}$. The intracellular accumulation of vincristine was measured by HPLC in $1 \times 10^{6}$ cells ( $\mathrm{n}=3$ ). ${ }^{*} \mathrm{P}<0.05$ and ${ }^{* *} \mathrm{P}<0.01$ vs. untreated HCT-8/VCR cells. (C) Cells were incubated with $50 \mu \mathrm{M}$ adriamycin and $10 \mu \mathrm{M}$ Rh123 for $3 \mathrm{~h}$ following treatment with 6-O-angeloylplenolin for $24 \mathrm{~h}$. The fluorescence intensity was detected in $1 \times 10^{4}$ cells $(\mathrm{n}=4)$. ${ }^{*} \mathrm{P}<0.05$ and ${ }^{* *} \mathrm{P}<0.01$ vs. untreated HCT-8/VCR cells; "P $<0.01$ vs. untreated HCT- 8 cells.

(1:10,000) conjugated with fluorescein isothiocyanate (FITC) (Rockland Immunochemicals, Inc., Limerick, PA, USA; cat. no. 611-1102) at room temperature for $30 \mathrm{~min}$ in dark. Over $2 \times 10^{4}$ events were acquired and analyzed by a FACScan flow cytometer with CellQuest software (version 5.1; BD Biosciences, Franklin Lakes, NJ, USA).

Western blot analysis. Following treatment with $0.35,0.7$ or $1.4 \mu \mathrm{M} 6-\mathrm{O}$-angeloylplenolin for $12 \mathrm{~h}$, the cytosolic and nuclear proteins in HCT-8/VCR cells were extracted described previously (26). A total of $20 \mu \mathrm{g}$ total cytosolic and nuclear proteins were separated by $12 \%$ SDS-PAGE. Following electrophoresis, the proteins were transferred to a polyvinylidene difluoride (PVDF) membrane, which were blocked with $3 \% \mathrm{BSA}$ at room temperature for $1 \mathrm{~h}$. The PVDF membranes were incubated with anti-YB-1 (monoclonal rabbit IgG; Cell Signaling Technology, Inc.) or rabbit anti-GAPDH antibody (dilution, 1:5,000; Sigma-Aldrich, Merck KGaA; cat. no. PLA0125) antibodies at $4^{\circ} \mathrm{C}$ for overnight. The primary antibodies were detected with anti-rabbit IgG conjugated to alkaline phosphatase (1:3,000 dilutions, Bio-Rad Laboratories,
Inc., Hercules, CA, USA; cat. no. 170-6518) to generate a BCIP/NBT (Promega Corporation, Madison, WI, USA; cat. no. S3771) signal. Gel analysis was performed with Image Lab 3.0 software (Bio-Rad Laboratories, Inc.).

Transient transfection and luciferase assay. Plasmid construction was performed as described previously $(7,27)$. HCT-8/VCR cells were seeded into six-well plates ( $3 \times 10^{5}$ cells/well) and incubated for $24 \mathrm{~h}$ before transfection. Using Lipofect Transfection reagent (Beijing Tiangen Biotech Co., Ltd., Beijing, China), the cells were co-transfected with $4 \mu \mathrm{g}$ /well plasmid pGL3-MDR1 (Promega Corporation, Madison, WI, USA). The sequence for MDR1 promoter was: Forward, 5'-CTAGAGAGGTGCAACGGA-3' (-198 to -181) and reverse, 5'-GCGGCCTCTGCTTCTTTGA-3' $(+25$ to +43$)$. Next, the cells were treated with $0.35,0.7$ or $1.4 \mu \mathrm{M} 6-\mathrm{O}$-angeloylplenolin for $24 \mathrm{~h}$. Firefly and Renilla luciferase activities in $1 \times 10^{4}$ cells/well were measured using the Dual-Luciferase Assay system (Promega Corporation) using a Microplate Luminometer (Berthold Technologies GmbH, Bad Wildbad, Germany). 
Table I. Cytotoxicity of drugs in HCT-8 and HCT-8/VCR cells by MTT assay.

\begin{tabular}{lcccc}
\hline & \multicolumn{3}{c}{$\mathrm{IC}_{50}$} \\
\cline { 2 - 5 } Cell line & $\mathrm{VCR}, \mu \mathrm{g} / \mathrm{ml}$ & $\mathrm{HEPT}, \mu \mathrm{g} / \mathrm{ml}$ & $\mathrm{MIT}, \mu \mathrm{g} / \mathrm{ml}$ & 6-O-angeloylplenolin, $\mu \mathrm{M}$ \\
\hline HCT-8 & $12.7 \pm 0.59$ & $23.3 \pm 0.47$ & $1.1 \pm 0.11$ & $5.97 \pm 0.47$ \\
HCT-8/VCR & $250 \pm 8.45^{\mathrm{a}}$ & $40 \pm 0.35^{\mathrm{a}}$ & $3.9 \pm 0.15^{\mathrm{a}}$ & $24.21 \pm 0.64^{\mathrm{a}}$ \\
HCT-8/VCR + 6-O-angeloylplenolin & $13.8 \pm 0.78^{\mathrm{b}}$ & $18.5 \pm 0.15^{\mathrm{b}}$ & $0.48 \pm 0.02^{\mathrm{b}}$ & - \\
\hline
\end{tabular}

Each value represents the mean \pm standard deviation $(\mathrm{n}=3)$. ${ }^{\mathrm{a}} \mathrm{P}<0.01 \mathrm{vs}$. untreated HCT- 8 cells; ${ }^{\mathrm{b}} \mathrm{P}<0.01$ vs. untreated HCT-8/VCR cells. IC ${ }_{50}$, half-maximal inhibitory concentration; VCR, vincristine; MIT, mitomycin; HEPT, hydroxycamptothecin.

Electrophoretic mobility shift assay (EMSA). HCT-8/VCR $\left(3 \times 10^{5}\right.$ cells/well) cells were treated with $0.35,0.7$ or $1.4 \mu \mathrm{M}$ 6-O-angeloylplenolin for $12 \mathrm{~h}$ and the EMSA was performed as described by Han et al (24). The DNA sequence of the ds-oligomer used was a CAAT-like motif (5'-ATCAGCATT CAGTCAATCCGGGCC-3') (5,7). The gels were stained using the EMSA kit (Invitrogen; Thermo Fisher Scientific, Inc.) as described by the manufacturer and images were captured using an Olympus Standard fluorescence microscope (Olympus Corporation, Tokyo, Japan). The magnification used was x100.

Animal study. Nude mice (BALB/c; female; age, 6-8 week; 20-22 g; n=5) were provided by Vital River Laboratories Co., Ltd. (Beijing, China), which were housed in barrier facilities on a 12 -h light/dark cycle at $23-25^{\circ} \mathrm{C}$ with free access to food and water. Each mouse was subcutaneously injected with $5 \times 10^{6} \mathrm{HCT}-8 / \mathrm{VCR}$ cells in the left dorsal flank. When the tumor reached about $150 \mathrm{~mm}^{3}$, the mice were randomly assigned to 5 groups and received the following treatments for 12 days: Control (PBS), 6-O-angeloylplenolin (7 mg/ $\mathrm{kg}$ per day, oral), VCR $(2.5 \mathrm{mg} / \mathrm{kg}$ per day, oral), VCR + 6-O-angeloylplenolin (3.5 $\mathrm{mg} / \mathrm{kg}$ per day, oral), VCR + 6-O-angeloylplenolin $(7 \mathrm{mg} / \mathrm{kg}$ per day, oral). Following 12 days, the tumors were isolated and weighed. The tumor growth inhibitory rate (IR) was calculated as follows: IR $(\%)=1-\left(\mathrm{TW}_{\text {treated }} / \mathrm{TW}_{\text {control }}\right) \times 100$. The protocol was approved by the Committee on the Ethics of Animal Experiments of the Capital Medical University.

Statistical analysis. Statistical analysis was performed using one-way analysis of variance followed by Dunnett's test (version 5.0; GraphPad Software, Inc., La Jolla, CA, USA). All results are presented as the mean \pm standard deviation. $\mathrm{P}<0.05$ was considered to indicate a statistically significant difference.

\section{Results}

MDR-reversing effect of 6-O-angeloylplenolin. HCT-8 and HCT-8/VCR cells were incubated with vincristine, mitomycin and hydroxycamptothecin for $24 \mathrm{~h}$ and subjected to MTT assays to assess cell viability. HCT-8/VCR cells were significantly more resistant to vincristine, 6-O-angeloylplenolin, mitomycin and hydroxycamptothecin than HCT-8 cells (Table I). Treatment with 1.4 $\mu \mathrm{M}$ 6-O-angeloylplenolin had no significant effect on the viability of HCT-8/VCR cells.
Therefore, the concentration of 6-O-angeloylplenolin was applied to indicate a reversal of resistance. HCT-8/VCR cells were co-incubated with $1.4 \mu \mathrm{M}$ 6-O-angeloylplenolin and one of three anti-cancer drugs vincristine, mitomycin or hydroxycamptothecin for $24 \mathrm{~h}$. The concentrations of vincristine, mitomycin or hydroxycamptothecin were $1,3,10,30,100$ and $300 \mu \mathrm{g} / \mathrm{ml}$. The results of the MTT assay revealed that $1.4 \mu \mathrm{M}$ 6-O-angeloylplenolin significantly increased the cytotoxicity of each of the three anticancer drugs on HCT-8/VCR cells (Table I).

Treatment with 6-O-angeloylplenolin increases the intracellular accumulation of vincristine, adriamycin and Rh123. Inhibiting drug efflux and increasing the intracellular accumulation of drugs is an effective way of overcoming drug resistance (24). To investigate whether 6-O-angeloylplenolin increased the intracellular accumulation of vincristine, adriamycin and Rh123 in HCT-8/VCR cells, HPLC and fluorescence intensity assays were performed. The results indicated that 6-O-angeloylplenolin significantly increased the intracellular accumulation of vincristine, adriamycin and Rh123 in HCT-8/VCR cells following treatment with 6-O-angeloylplenolin for $24 \mathrm{~h}$ (Fig. 1B and C; $\mathrm{P}<0.01$ ).

Treatment with 6-O-angeloylplenolin does not alter the expressionofMRPI andYB-1.Itisreported that vincristineissusceptible to common mechanisms of multidrug resistance, including the overexpression of P-gp (28). Here, 6-O-angeloylplenolin did not affect the expression of MRP1 in colon cancer cells. This result indicated that 6-O-angeloylplenolin reversed vincristine resistance by suppressing $M D R I$ expression. Moreover, 6-O-angeloylplenolin had no effect on the expression of $Y B X 1$, which encodes YB-1 (Fig. 2A and B). These results indicated that 6-O-angeloylplenolin suppressed YB-1 nuclear translocation, but not YB-1 expression.

Treatment with 6-O-angeloylplenolin downregulates expression of MDR1 mRNA and protein. The overexpression of $M D R 1$ and its protein product have been associated with the MDR phenotype (1). Therefore, the expression of MDRI mRNA was assessed by RT-PCR and flow cytometry analysis. Whether 6-O-angeloylplenolin could downregulate the expression of MDR1 in HCT-8/VCR cells was examined. The results of this analysis revealed that 6-O-angeloylplenolin decreased MDR1 expression in HCT-8/VCR cells (Fig. 2), 

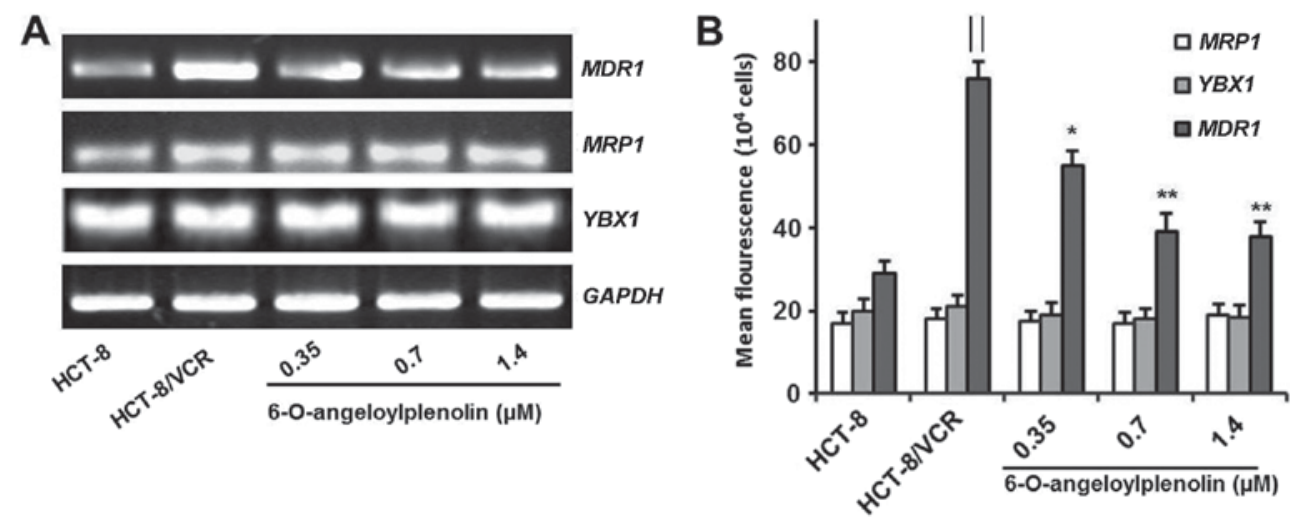

Figure 2. Effect of 6-O-angeloylplenolin on MDR1, MRP1 and YBX1 mRNA level. Cells were treated with 6-O-angeloylplenolin for $12 \mathrm{~h}$. RT-PCR analysis was applied to expression of MDR1, MRP1, and YBX1. (A) Electrophoresis gel image of RT-PCR products. (B) The ratio (to GAPDH) of in the cells treated with different concentrations of $6-\mathrm{O}$-angeloylplenolin by scanning densitometry $(\mathrm{n}=4)$. ${ }^{*} \mathrm{P}<0.05$ and ${ }^{* *} \mathrm{P}<0.01$ vs. HCT-8/VCR cells; "P<0.01 vs. untreated HCT- 8 cells. RT-PCR, reverse transcription-polymerase chain reaction; MDR1, ATP-binding cassette sub-family B member 1; MRP1, ATP binding cassette subfamily $\mathrm{C}$ member 1; YBXI, Y-box binding protein 1.
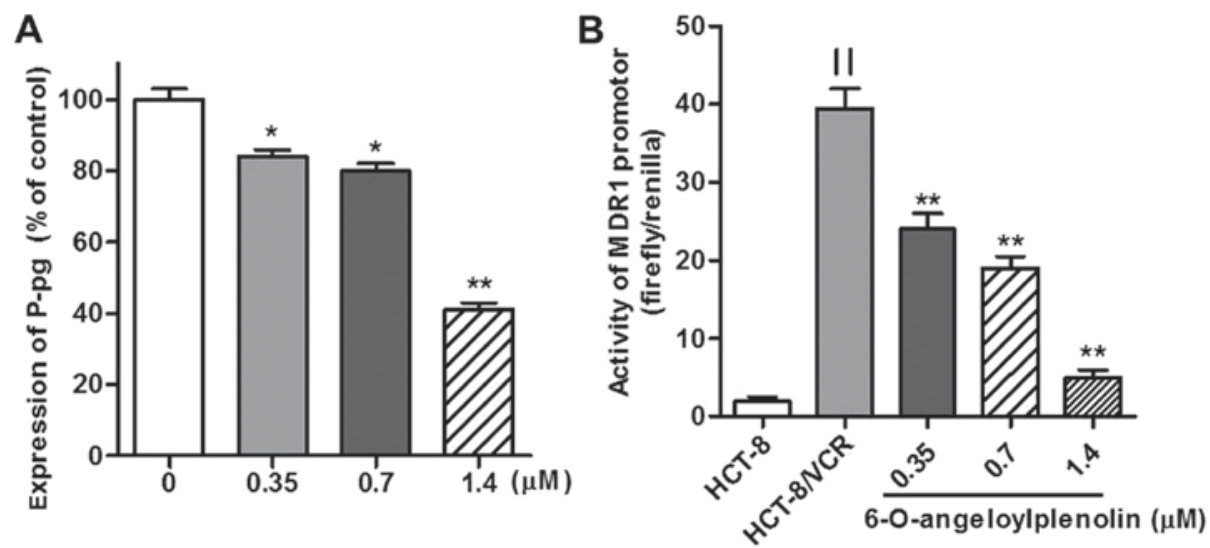

Figure 3. Effect of 6-O-angeloylplenolin on protein expression of MDR1 and activity of the MDR1 promoter. (A) HCT-8/VCR cells were treated with 6-O-angeloylplenolin for $24 \mathrm{~h}$, and flow cytometry assay was performed $(\mathrm{n}=4)$. ${ }^{*} \mathrm{P}<0.05$ and ${ }^{* *} \mathrm{P}<0.01$ vs. untreated HCT-8/VCR cells. (B) Cells were treated with 6-O-angeloylplenolin for 2 days following co-transfection with pGL3-MDR and pRL-TK. The activity of MDR1 promoter was measured using a dual-luciferase assay. Data are represented as mean \pm standard deviation $(n=4)$. ${ }^{*} \mathrm{P}<0.05$ and ${ }^{* *} \mathrm{P}<0.01$ vs. untreated HCT-8/VCR cells; " $\mathrm{P}<0.01$ was compared with untreated HCT-8 cells. MDR1, ATP-binding cassette sub-family B member 1.

in parallel with a reduction of the protein expression of MDRI (Fig. 3A).

Treatment with 6-O-angeloylplenolin suppresses MDR1 promoter activity. To determine whether the CAAT segment of the MDR1 promoter was regulated by 6-O-angeloylplenolin or not, the wild-type $M D R 1$ promoter (residues -198 to $+43,241$ bp) DNA fragment was cloned into a luciferase-expressing pGL3-basic vector to construct pGL3-MDR, as described previously (27). The data revealed that there was an 18 -fold increase in $M D R 1$ promoter activity in HCT-8/VCR cells transiently transfected with dual-reporter gene vectors, compared with the level in HCT-8 (Fig. 3B). MDR1 promoter activity was significantly decreased in HCT-8/VCR cells following incubation with 6-O-angeloylplenolin for $24 \mathrm{~h}$ (Fig. 3B).

6-O-angeloylplenolin suppresses YB-1 nuclear translocation. Whether the expression and localization of YB-1 is associated with the expression of MDRl gene is key to understanding the mechanism of P-gp action. To confirm the effect of 6-O-angeloylplenolin on YB-1 nuclear translocation, western blot analysis was performed. Compared with HCT-8 cells, nuclear translocation of YB-1 was enhanced in HCT-8/VCR cells. The data revealed that 6-O-angeloylplenolin effectively inhibited the nuclear translocation of YB-1 in HCT-8/VCR cells (Fig. 4A-C).

6-O-angeloylplenolin downregulates MDR1 expression by decreasing binding of MDR1 promoter with nuclear transcription factors. A number of studies $(29,30)$ have provided evidence implicating complex mechanisms for the transcriptional regulation of $M D R 1$ in human cancer cells. Since the present study demonstrated that 6-O-angeloylplenolin could inhibit the expression of MDRI mRNA, it was necessary to examine whether 6-O-angeloylplenolin had any effect on $M D R 1$ promoter. An EMSA was performed using a probe from the MDR1 promoter sequence, -86 to $-67 \mathrm{bp}$. The amount of specific protein complex interacting with the probe was lower in the HCT-8 cells than in HCT-8/VCR cells (Fig. 4D; lanes 2-3). 
A

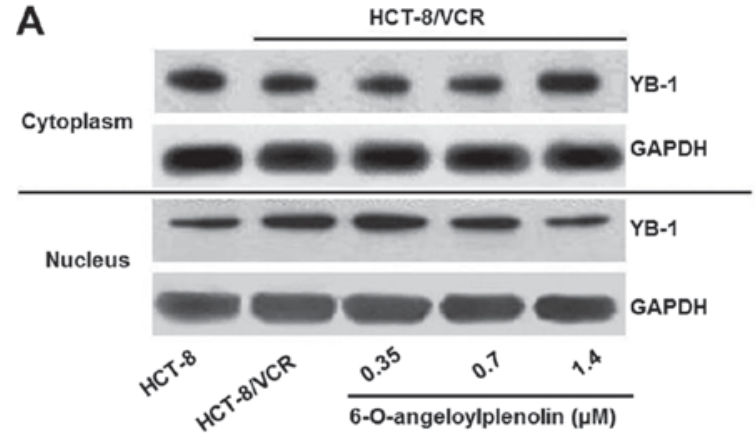

C

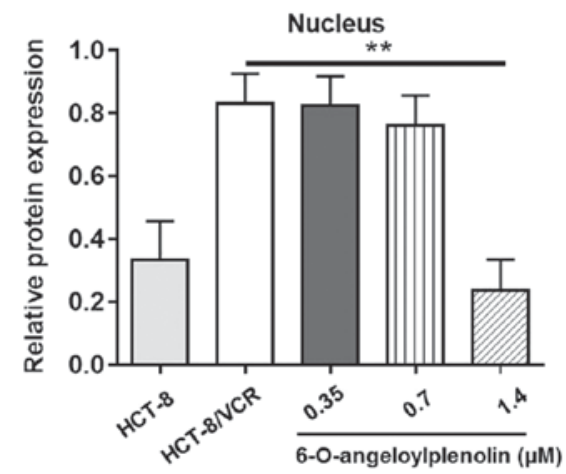

B

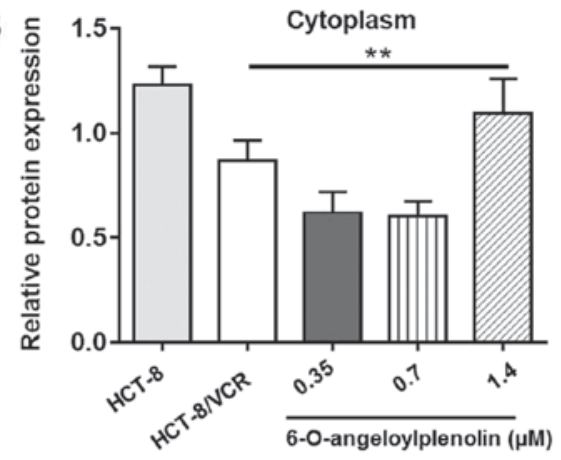

D

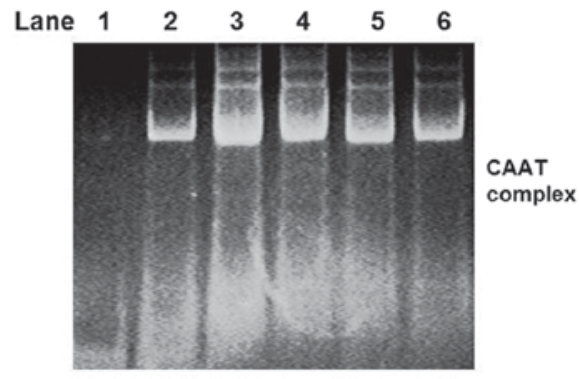

Figure 4. Effect of 6-O-angeloylplenolin on YB-1 nuclear translocation and interaction between the nuclear protein and the CAAT region of the MDRI promoter. (A) The cytoplasm and nucleolus protein were extracted following incubation with 6-O-angeloylplenolin for $12 \mathrm{~h}$, resolved using SDS-PAGE, and western blot analysis was performed with the indicated antibodies. GAPDH was used as the loading control. (B) The quantification of the YB-1 protein expression in the cytoplasm. (C) Quantification of the YB-1 protein expression in cytoplasm. ${ }^{* *} \mathrm{P}<0.01$ vs. untreated HCT-8/VCR cells. (D) The nucleolar protein was extracted following incubation with 6-O-angeloylplenolin for $12 \mathrm{~h}$, and the amount of complexed nuclear protein and DNA were measured using an electrophoretic mobility shift assay. Lane 1, only nuclear extracts; lane 2, probe incubated with nuclear extracts of HCT-8 cells; lane 3, probe incubated with nuclear extracts of HCT-8/VCR cells; lane 4, probe incubated with nuclear extracts of HCT-8/VCR cells following treatment with $0.35 \mu \mathrm{M} 6$-O-angeloylplenolin; lane 5 , probe incubated with nuclear extracts of HCT-8/VCR cells following treatment with $0.7 \mu \mathrm{M} 6$-O-angeloylplenolin; lane 6 , probe incubated with nuclear extracts of HCT-8/VCR cells following treatment with $1.4 \mu \mathrm{M}$ 6-O-angeloylplenolin. YB-1, Y-box binding protein 1.

Treatment with 6-O-angeloylplenolin decreased the number of protein/DNA complexes in HCT-8/VCR cells (Fig. 4B, lanes 3-6). This result indicated that 6-O-angeloylplenolin inhibited the binding of nuclear proteins to the CAAT region of the MDRl promoter in HCT-8/VCR cells, which could result in the inhibition of $M D R l$ expression.

\section{6-O-angeloylplenolin reverses $\mathrm{VCR}$ resistance in $\mathrm{HCT/VCR}$} xenograft model. To evaluate whether 6-O-angeloylplenolin could reverse vincristine resistance in vivo, a HCT/VCR xenograft model was established by injecting HCT/VCR cells into the left dorsal flanks of nude mice. The data demonstrated that 6-O-angeloylplenolin or vincristine treatment alone had no effect on tumor growth. However, the combination of 6-O-angeloylplenolin with vincristine significantly inhibited tumor growth (Fig. 5A and B). In addition, the body weights of mice were stable, indicating the combination treatments were tolerable (Fig. 5C).

\section{Discussion}

Resistance to chemotherapeutics remains a major cause of cancer treatment failure. Thus, in addition to investigating more efficient therapeutic drugs, there is a requirement to develop compounds to inhibit MDR activity or to synergize with existing treatments. The current study revealed that
6-O-angeloylplenolin treatment reversed vincristine resistance in HCT-8/VCR cells, increasing the intracellular accumulation. MDR is often associated with the overexpression of MDRl, which causes the enhancement of drug efflux pump activity and drug resistance (29). Treatment with 6-O-angeloylplenolin inhibited the expression or function of P-gp, data that were further supported by RT-PCR, flow cytometry and promoter activity analysis.

Several approaches to overcoming MDR have been proposed $(12,28,29)$; of them, inhibition of MDR-associated genes has promise. P-gp is encoded by $M D R 1$, which was investigated in the present study. The expression of $M D R I$ was depleted following 6-O-angeloylplenolin administration. Besides P-gp, MRP1 is another protein that is important to MDR; it is encoded by MRP1. The results of the present study indicated that the mRNA level of $M R P 1$ was unchanged following 6-O-angeloylplenolin treatment (Fig. 2) and that 6-O-angeloylplenolin exerts its main effect via regulating the expression of MDRl in vitro.

Previous reports have demonstrated that YB-1 activity is closely associated with the expression of MDRl in vivo and in vitro (5-9). Treatment with 6-O-angeloylplenolin decreased the level of YB-1 in nucleus and complexes of this nuclear protein with $M D R 1$ promoter in a dose-dependent manner. However, 6-O-angeloylplenolin regulating the expression of $Y B X 1$ on mRNA level was not observed. Therefore, 6-O-angeloylplenolin 
A

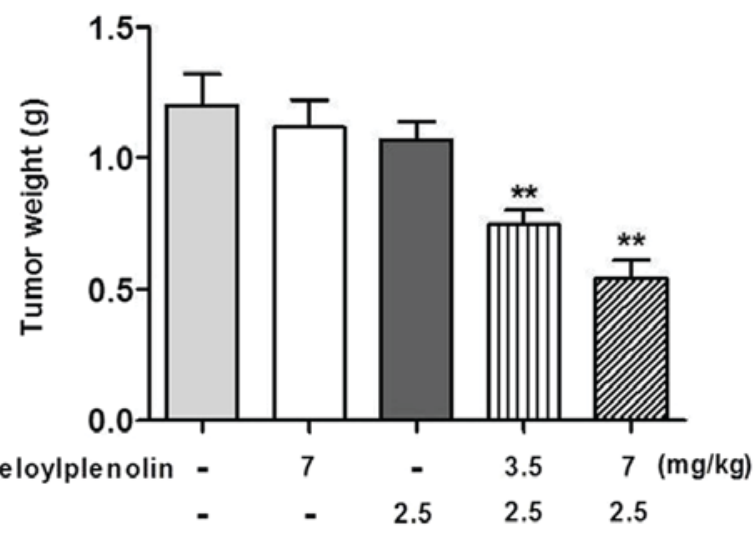

B

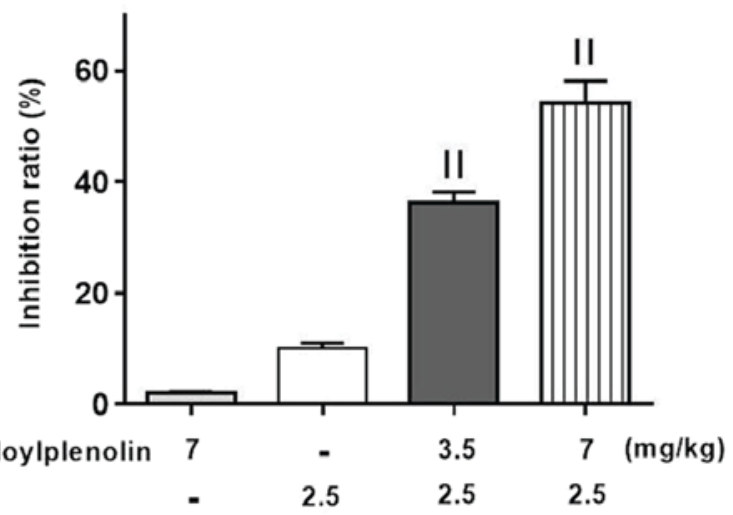

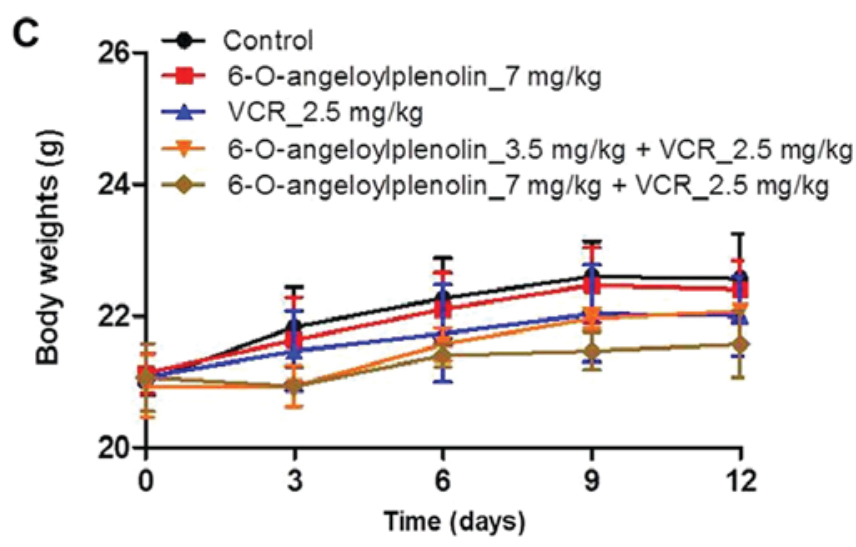

Figure 5. Treatment with 6-O-angeloylplenolin reversed vincristine resistance in the HCT/VCR xenograft model. (A) The tumors were isolated and weighted after 12 days of treatment. ${ }^{* *} \mathrm{P}<0.01$ were compared with control group. (B) The tumor growth inhibition ratio was calculated $(\mathrm{n}=5)$. "P<0.01 was compared with vincristine treatment alone. (C) The body weights of mice were monitored on the indicated day $(n=5)$. VCR, vincristine.

regulated the expression of MDR1 by inhibiting YB-1 nuclear translocation, not by depressing its expression. These findings differ from previous reports $(9,12)$, which might be due to the different tumor type. Therefore, these novel results shed light on the mechanism of chemotherapy resistance in colon cancer. These results provide evidence for the combination use of 6-O-angeloylplenolin with vincristine in patients with refractory colon cancer. However, there were certain limitations to the current study. The detailed interaction between YB1 and MDR1 following 6-O-angeloylplenolin treatment in colon cancer was not clarified. Future studies should focus on the protein kinase B-nuclear factor- $\mathrm{B}-\mathrm{YB}-1-\mathrm{MDR} 1$ and tumor protein p53-YB-1-MDR1 signaling pathways in the future.

Taken together, the results of the present study indicated that 6-O-angeloylplenolin displayed a significant antitumor activity by reserving drug resistance. The effect of 6-O-angeloylplenolin was exerted via inhibition of the intracellular accumulation of YB-1 and the expression of MDRl, resulting in a decrease in efflux pump activity. These results demonstrated that 6-O-angeloylplenolin may represent a potential anticancer drug adjuvant with the potential to reverse drug resistance.

\section{Acknowledgements}

Not applicable.

\section{Funding}

The present study was funded by: Key Projects in the National Science \& Technology Pillar Program (grant no. 2015BAI09B01), National Science Foundation of China (grant no. 31572348) and Support Project of High-level Teachers in Beijing Municipal Universities in Period of 13th Five-year Plan (grant no. IDHT20170516).

\section{Availability of data and materials}

The datasets used and/or analyzed during the present study are available from the corresponding author on reasonable request.

\section{Authors' contributions}

CL was mainly responsible for study design, data analysis, manuscript development and conduction of experiments, including cell culture, MTT assay, RT-PCR, and the accumulation assay of vincristine, adriamycin and Rh123. HW performed flow cytometry assay of HCT-8/VCR cells, western blot analysis, and assisted with statistical analysis. YY helped with transient transfection and luciferase assay. JL was involved in electrophoretic mobility shift assay and animal study. ZC performed experiments and reviewed and revised the manuscript. 


\section{Ethics approval and consent to publish}

Ethics approval for animal study was given by the local research ethics committee at East China University of Science and Technology.

\section{Consent for publication}

There are no human participants, human data or human tissue involved in this manuscript.

\section{Competing interests}

The authors declare no competing financial interests.

\section{References}

1. Gottesman MM, Fojo T and Bates SE: Multidrug resistance in cancer: Role of ATP-dependent transporters. Nat Rev Cancer 2: 48-58, 2002.

2. Ambudkar SV, Dey S, Hrycyna CA, Ramachandra M, Pastan I and Gottesman MM: Biochemical, cellular, and pharmacologica aspects of the multidrug transporter. Annu Rev Pharmacol Toxicol 39: 361-398, 1999.

3. Kohno K, Sato S,Uchiumi T, Takano H, Tanimura H, Miyazaki M, Matsuo K, Hidaka K and Kuwano M: Activation of the human multidrug resistance 1 (MDR1) gene promoter in response to inhibitors of DNA topoisomerases. Int J Oncol 1: 73-77, 1992.

4. Uchiumi T, Kohno K, Tanimura H, Matsuo K, Sato S, Uchida Y and Kuwano M: Enhanced expression of the human multidrug resistance 1 gene in response to UV light irradiation. Cell Growth Differ 4: 147-157, 1993.

5. Stein U, Jürchott K, Walther W, Bergmann S, Schlag PM and Royer HD: Hyperthermia-induced nuclear translocation of transcription factor YB-1 leads to enhanced expression of multidrug resistance-related ABC transporters. J Biol Chem 276: 28562-28569, 2001

6. Kuwano M, Oda Y, Izumi H, Yang SJ, Uchiumi T, Iwamoto Y, Toi M, Fujii T, Yamana H, Kinoshita H, et al: The role of nuclear Y-box binding protein 1 as a global marker in drug resistance. Mol Cancer Ther 3: 1485-1492, 2004.

7. Ogretmen B and Safa AR: Identification and characterization of the MDR1 promoter-enhancing factor 1 (MEF1) in the multidrug resistant HL60/VCR human acute myeloid leukemia cell line. Biochemistry 39: 194-204, 2000.

8. Vaiman AV, Stromskaya TP, Rybalkina EY, Sorokin AV, Guryanov SG, Zabotina TN, Mechetner EB, Ovchinnikov LP and Stavrovskaya AA: Intracellular localization and content of YB-1 protein in multidrug resistant tumor cells. Biochemistry (Mosc) 71: 146-154, 2006.

9. Bargou RC, Jürchott K, Wagener C, Bergmann S, Metzner S, Bommert K, Mapara MY, Winzer KJ, Dietel M, Dörken B and Royer HD: Nuclear localization and increased levels of transcription factor YB-1 in primary human breast cancers are associated with intrinsic MDR1 gene expression. Nat Med 3: 447-450, 1997.

10. Fujita T, Ito K, Izumi H, Kimura M, Sano M, Nakagomi H, Maeno K, Hama Y, Shingu K, Tsuchiya S, et al: Increased nuclear localization of transcription factor Y-box binding protein 1 accompanied by up-regulation of P-gp in breast cancer pretreated with paclitaxel. Clin Cancer Res 11: 8837-8844, 2005

11. Saji H, Toi M, Saji S, Koike M, Kohno K and Kuwano M: Nuclear expression of YB-1 protein correlates with P-glycoprotein expression in human breast carcinoma. Cancer Lett 190: 191-197, 2003.

12. Cole SP, Bhardwaj G, Gerlach JH, Mackie JE, Grant CE, Almquist KC, Stewart AJ, Kurz EU, Duncan AM and Deeley RG: Overexpression of a transporter gene in a multidrug-resistant human lung cancer cell line. Science 258: 1650-1654, 1992.

13. Kaszubiak A, Kupstat A, Müller U, Hausmann R, Holm PS and Lage H: Regulation of MDR1 gene expression in multidrug-resistant cancer cells is independent from YB-1. Biochem Biophys Res Commun 357: 295-301, 2007.
14. Chan CO, Jin DP, Dong NP, Chen SB and Mok DK: Qualitative and quantitative analysis of chemical constituents of Centipeda minima by HPLC-QTOF-MA\& HPLC-DAD. J Pharm Biomed Anal 125: 400-407, 2016.

15. Taylor RS and Towers GH: Antibacterial constituents of the Nepalese medicinal herb, Centipeda minima. Phytochemistry 47: 631-634, 1998.

16. Li CL, Wu HZ, Huang YP, Yang YF, Liu YW and Liu JW: Brevilin $\mathrm{A}$ induces apoptosis through a mitochondrial/caspase and NF- $\kappa$ B pathway in human leukemia HL-60 cells. Biomed Pharmacother 62: 401-409, 2008.

17. Liu YQ, Wang XL, Cheng X, Lu YZ, Wang GZ, Li XC, Zhang J, Wen ZS, Huang ZL, Gao QL, et al: Skpl in lung cancer: Clinical significance and therapeutic efficacy of its small molecule inhibitors. Oncotarget 6: 34953-34967, 2015.

18. Liu Y, Chen XQ, Liang HX, Zhang FX, Zhang B, Jin J, Chen YL, Cheng YX and Zhou GB: Small compound 6-O-angeloylplenolin induces mitotic arrest and exhibits therapeutic potentials in multiple myeloma. PLoS One 6: e21930, 2011.

19. Muñoz-Martínez F, Lu P, Cortés-Selva F, Pérez-Victoria JM, Jiménez IA, Ravelo AG, Sharom FJ, Gamarro F and Castanys S: Celastraceae sesquiterpenes as a new class of modulators that bind specifically to human P-glycoprotein and reverse cellular multidrug resistance. Cancer Res 64: 7130-7138, 2004.

20. Mosman T: Rapid colorimetric assay for cellular growth and survival, application to proliferation and cytotoxicity assays. J Immunol Methods 65: 55-63, 1983.

21. Zhang Q, Wei DZ and Liu JW: In vivo reversal of doxorubicin resistance by (-)-epigallocatechin gallate in a solid human carcinoma xenograft. Cancer Lett 208: 179-186, 2004.

22. National Pharmacopoeia Committee: National Pharmacopoeia Committee Pharmacopoeia of the People's Republic of China. Vol 1. Chemical Industry Press, pp 2721, Beijing, 2015.

23. Wei D, Mei Y and Liu J: Quantification of doxorubicin and validation of reversal effect of tea polyphenols on multidrug resistance in human carcinoma cells. Biotechnol Lett 25: 291-294, 2003.

24. Han SO, Inui M and Yukawa H: Expression of Corynebacterium glutamicum glycolytic genes varies with carbon source and growth phase. Microbiology 153: 2190-2202, 2007.

25. Constable PA, Lawrenson JG, Dolman DE, Arden GB and Abbott NJ: P-Glycoprotein expression in human retinal pigment epithelium cell lines. Exp Eye Res 83: 24-30, 2006.

26. Braga F, Ayres-Saraiva D, Gattass CR and Capella MA: Oleanolic acid inhibits the activity of the multidrug resistance protein $\mathrm{ABCC} 1$ (MRP1) but not of the $\mathrm{ABCB} 1$ (P-glycoprotein): Possible use in cancer chemotherapy. Cancer Lett 248: 147-152, 2007.

27. Yu ST, Chen TM, Tseng SY and Chen YH: Tryptanthrin inhibits MDR1 and reverses doxorubicin resistance in breast cancer cells. Biochem Biophys Res Commun 358: 79-84, 2007.

28. Boháčová V, Sulová Z, Dovinová I, Dovinová I, Poláková E, Barančík M, Uhrík B, Orlický J and Breier A: L1210 cells cultivated under the selection pressure of doxorubicin or vincristine express common mechanisms of multidrug resistance based on the overexpression of P-glycoprotein. Toxicol In Vitro 20: $1560-1568,2006$.

29. Zhang H, Jing X, Wu X, Hu J, Zhang X, Wang X, Su P, Li W and Zhou G: Suppression of multidrug resistance by rosiglitazone treatment in human ovarian cancer cells through downregulation of FZD1 and MDR1 genes. Anticancer Drugs 26: 706-715, 2015.

30. Yun M, Lee D, Park MN, Kim EO, Sohn EJ, Kwon BM and Kim SH: Cinnamaldehyde derivative (CB-PIC) sensitizes chemo-resistant cancer cells to drug-induced apoptosis via suppression of MDR1 and its upstream STAT3 and AKT signaling. Cell Physiol Biochem 35: 1821-1830, 2015.

This work is licensed under a Creative Commons Attribution-NonCommercial-NoDerivatives 4.0 International (CC BY-NC-ND 4.0) License. 